This is the author's final, peer-reviewed manuscript as accepted for publication. The publisher-formatted version may be available through the publisher's web site or your institution's library.

\title{
Expectancy-value models for the STEM persistence plans of ninth-grade, high-ability students: a comparison between Black, Hispanic, and White students
}

Lori Andersen, Thomas J. Ward

How to cite this manuscript

If you make reference to this version of the manuscript, use the following information:

Andersen, L., \& Ward, T. J. (2014). Expectancy-value models for the STEM persistence plans of ninth-grade, high-ability students: A comparison between Black, Hispanic, and White students. Retrieved from http://krex.ksu.edu

\section{Published Version Information}

Citation: Andersen, L., \& Ward, T. J. (2014). Expectancy-value models for the STEM persistence plans of ninth-grade, high-ability students: A comparison between Black, Hispanic, and White students. Science Education, 98(2), 216-242.

Copyright: @ 2013 Wiley Periodicals, Inc.

Digital Object Identifier (DOI): doi: 10.1002/sce.21092

Publisher's Link: http://onlinelibrary.wiley.com/doi/10.1002/sce.21092/full

This item was retrieved from the K-State Research Exchange (K-REx), the institutional repository of Kansas State University. K-REx is available at http://krex.ksu.edu 
Expectancy-Value Models for the STEM Persistence Plans of Ninth-Grade, High-Ability Students: A Comparison Between Black, Hispanic, and White Students

\author{
Lori Andersen \\ Kansas State University \\ Thomas J. Ward \\ The College of William and Mary
}

\title{
Citation:
}

Andersen, L., \& Ward, T. J. (2014). Expectancy-value models for the STEM persistence plans of ninth-grade, high-ability students: A comparison between Black, Hispanic, and White students. Science Education, 98, 2, 216-242. doi: 10.1002/sce.21092 
Recent reports have documented an urgent need for science, technology, engineering, and mathematics (STEM) innovators and experts in the US (National Academy of Sciences, 2007; National Science Board, 2010). However, a much smaller proportion of US students major in the sciences or engineering compared to other countries, and $35 \%$ of the $\mathrm{PhDs}$ in the US STEM workforce are foreign-born (Atkinson \& Mayo, 2011). The acute underrepresentation of minorities in these disciplines is evidence of a large amount of undeveloped talent in these populations. In 2008, Blacks and Hispanics were underrepresented by more than $50 \%$ in undergraduate engineering programs compared to their representation in the 18 to 24 -year-old US population, while White students are overrepresented by more than $10 \%$ (National Science Foundation, 2012). These same levels of underrepresentation also exist in gifted education (US Department of Education, 2008). This disproportionate representation is evidence that the potentials of Black and Hispanic students who have high ability are not being developed.

Future scientists, mathematicians and engineers should come from the talent pool consisting of all students who have high ability or demonstrate superior performance in mathematics and science. Demographic trends in the US indicate that population diversity is rapidly increasing. Understanding the variables that facilitate STEM persistence for talented Black and Hispanic students is important, not only to provide equitable outcomes for these students compared to the outcomes attained by their White and Asian peers, but also to ensure the viability of the US STEM workforce. Students must take appropriate science and mathematics coursework in high school to ensure their readiness to enter postsecondary STEM programs (Lynch, 2011). In order to increase the numbers of high-ability, underrepresented minority (URM) students who enter trajectories of STEM talent development, the process by 
which these students plan to take the requisite preparatory coursework must be understood. This article presents the results of a study of the variables that predict ninth-grade, high-ability students' STEM persistence plans.

\section{Framework}

The Eccles et al. (1983) expectancy value model of achievement-related choices is the theoretical framework for this study. According to this model, students' decisions to persist in taking mathematics and science coursework are determined by their personal assessments of the likelihood of success in, and the relative value that they assign to, the options perceived to be available. Expectations for success in science and mathematics are represented by science and mathematics self-efficacy. Relative importance is described by subjective task value (STV), that construes the value of mathematics and science courses in terms of four dimensions: (1) the utility value as related to the student's future goals, (2) the intrinsic value based on enjoyment, (3) the attainment value based on consistency with student identity, and (4) the cost determined by perceptions of time taken away from other activities or the potential negative responses of peers (Eccles, 2009). Subjective task value is synthesized based on inputs from culture, socializers, and the individual's experiences. In other words, STV is constructed during the identity formation process by which adolescents select activities that reflect the salient characteristics of groups with which they identify (Eccles, 2009).

The plans of high-ability, URM, ninth-grade students to continue their studies of mathematics and science were studied because previous research has shown that reentry into the STEM pipeline is rare after high school and that career plans made in high school predict future completion of STEM degrees (Maltese \& Tai, 2011; Syed, Azmitia, \& Cooper, 2011; Tai, Liu, Maltese, \& Fan, 2006). Before high school, all students are in the science and mathematics 
pipeline by default. In high school, students follow coursework and career preparation paths that were selected based on perceived ability, motivation, and opportunity. A key to post-secondary STEM talent development is appropriate preparatory coursework in high school (Lynch, 2011). Therefore, a better understanding of the variables that affect these selections could facilitate increases in the numbers of URM students who plan to persist.

\section{STEM Persistence Studies}

While previous studies have examined variables associated with STEM persistence using national data, attention has generally been focused on the relative deficits of those students who exit the pipeline. The external validity of these studies is limited by the lack of diversity in the participants. By treating race as one of many predictor variables in a model, most researchers have assumed that variables operate identically across all racial and socioeconomic groups (e.g. Maltese \& Tai, 2011; Mau, 2003). Extensive reviews of this literature already exist (Lee \& Luykx, 2006; Maltese \& Tai, 2011). In summary, previous research has identified deficits in preparatory coursework as a reason why students exit the STEM pipeline (Lee \& Luykx, 2006). Early interest was identified as a predictor of who earned a STEM degree (Tai et al., 2006). Taking a greater number of, and more rigorous, mathematics and science courses increased the chances of pursuing a STEM degree (Maltese \& Tai, 2011). Fewer Black and Hispanic students completed advanced coursework in mathematics and science compared to their Asian and White peers. However, those who did were equally as likely to complete STEM degrees (Tyson, Lee, Borman, \& Hanson, 2007). Students from underrepresented groups have been shown to be at greater risk of leaving a STEM major (Bonous-Harnmarth, 2000). Thus, previous research has revealed the required academic paths (advanced high school mathematics and science) to achieve and the demographics of who was more likely to achieve a STEM degree (Asian, White, and 
higher SES), but has not examined why many URM high school students who have high ability in mathematics and science take these courses or pursue these degrees. One group of researchers found that career considerations preceded course-taking plans for Black high school students. This finding places the causal order of career choice and course taking asserted by previous research in question (Lewis \& Connell, 2005; Thompson \& Lewis, 2005). Nonetheless, previous research has not separated the variables that influence persistence by race; thus, separate group analyses are necessary to understand and compare how predictor variables operate in different groups (Lee \& Luykx, 2006). This study aims to fill this gap in the literature.

Expectations for Success. Persistence is predicted by students' expectations for success in STEM. These expectations were often operationalized as domain-specific self-efficacy, or confidence in the ability to successfully complete tasks within a domain. Self-efficacy was more important than achievement to occupational choice decisions (Bandura, Barbaranelli, Caprara, \& Pastorelli, 2001; Eccles, 2005). Students who had higher self-efficacy or an interest in math and science were more likely to continue studies of those subjects, after controlling for achievement and socioeconomic status (Simpkins, Davis-Kean, \& Eccles, 2006). Mathematics self-efficacy and academic proficiency of eighth grade students predicted who would persist in aspiring to a science and engineering career (Mau, 2003). However, the participants in these studies were predominantly White and of mixed ability. In large samples of middle school students, mathematics and science self-efficacy was related to goals and intentions for Mexican-American, eighth grade students (Navarro, Flores, \& Worthington, 2007) and for inner city, low-SES students (Fouad \& Smith, 1996). In summary, previous research supports the importance of selfefficacy to occupational choice and course taking plans in groups of mixed ability students. 
However, the relative importance of domain specific self-efficacy to high-ability students' persistence plans is not known because of a lack of previous research.

Subjective task value. Two studies have been conducted using data from the National Education Longitudinal Study of 1988 (NELS: 88) that examined the effects of STV on persistence. First, early interest in a STEM career was sufficient to sustain students in the pipeline. Students who planned on pursuing a STEM career were more than twice as likely to earn a college degree in the sciences than students who did not have such plans, after controlling for student background and mathematics achievement (Tai et al., 2006). Eighth grade students' perceptions of the science utility value, a component of STV, was a better predictor of who would complete a STEM degree than mathematics or science achievement test scores (Maltese \& Tai, 2011). These studies support the predictive value of the intrinsic and utility value components of STV, however, no previous studies were found that examined the predictors of STEM persistence within a nationally representative sample of high-ability students.

Few studies have examined racial or ethnic differences in subjective task value. Zarrett and Malanchuk (2005) studied Black students' decisions to pursue careers in information technology. Black students were equally as likely to consider a career in computers as White students. Students' perceived ability, value of a domain, and the influence of socializers and peers on students' decision to pursue an information technology career were significant effects. These findings support the relevance of STV to Black students' career decisions.

There have been no empirical studies of high-ability, high school students' STV for STEM. According to expectancy-value theory, students who place a high STV on mathematics and science should be motivated to take such coursework. Subjective task value will vary within and across racial and ethnic groups because of the differential effects of culture and socializers 
on student identities (Eccles, 2009; Simpkins \& Davis-Kean, 2005). For example, the compatibility of doing mathematics and science with the individual's identity is the source of attainment value, therefore components of that identity such as race, ethnicity, gender, and culture will affect the STV that is constructed for science and mathematics.

Race, ethnicity, culture, and STV. The four components of STV are each affected by the racial, ethnic, and cultural identity of the student and the interactions of these attributes with STEM culture. For example, a lack of same-race role models or prominent historical figures in science or mathematics may prevent minority students from identifying with STEM domains. These students may feel as though they must be assimilated and give up their racial identity to succeed (Cooper, 2011). Many minority students may be less likely to view science and mathematics coursework as having a high utility value because of a lack of evidence of the successes of people like themselves, as compared to White male students who are presented with ample evidence of the successes of similar people in science (Hines, 2003). Science and mathematics careers may not seem like reasonable possibilities for personal goals to minority students (Archer et al., 2010; Archer, Hollingworth, \& Halsall, 2007). Lewis and Connell (2005) found that a majority of Black students' science and mathematics course taking decisions were based on utility value or interest. Lower utility values caused by a lack of connection between STEM courses and students' personal goals contribute to a lower subjective task value and reduce the likelihood of plans to persist.

Incompatible identities. Adolescence is a period focused on identity formation, including the development of academic and occupational identities (Erikson, 1968). Students develop a better sense of their relative competencies and the values that self-esteem is based upon during this process (Wigfield \& Wagner, 2005). Occupations are an important source of 
identity and adolescents choose future occupations based, in part, on how well their perceptions of who typically performs that kind of work, and what that work entails, fit with their identities (Bandura et al., 2001). Science is a subculture of white, male, western culture (Barba, 1998; Hines, 2003). Stereotypes that are associated with STEM are likely to conflict with components of students' gender, ethnic, or racial identities and prevent the integration of science into their identities (Archer et al., 2010; Archer et al., 2007; Taconis \& Kessels, 2009). For example, the culture of science is perceived to be masculine, competitive, individualistic, cut-throat, and isolated while many minority students learning styles demonstrate preferences for collaboration, group work, cooperation, and social learning (Ford, 2011; Heilbronner, 2011; Seymour \& Hewitt, 1997). Furthermore, STEM is often associated with social attributes that are undesirable to adolescents, which discourages the selection of such occupations. These points of potential cultural conflict mean that minority students may have lower degrees of identification with, and thus a lower degree of attainment value for, science than non-minority students. Attainment value and STV are reduced when science identity is lower which inhibits persistence. Thus, differences in the STV that students construct for science and mathematics may explain differences in persistence plans.

This study investigated the expectations for success and the STV that high-ability students have for science and mathematics by comparing the effects of factors such as selfefficacy, attainment value, utility value, intrinsic interest and cost on these students' plans to persist. The STEM persistence plans of high-ability students were hypothesized to be a function of these variables. Based on the Eccles et al. (1983) model, it was hypothesized that students who have high expectations for success, have intrinsic interest, see a high degree of utility in taking science and mathematics courses related to their future goals, find science and 
mathematics consistent with their identity, and have positive perceptions of the cost of taking science and mathematics courses are more likely to plan to persist. The current investigation explores the relative importance of these factors.

\section{Research Questions}

This investigation used a sample of high-ability, ninth grade students to study variables that may be associated with their plans to persist in STEM. Based on the Eccles et al. (1983) model and the review of the literature, the following hypotheses were made:

1) Each of the two measures of individuals' expectations for success in STEM, mathematics and science self-efficacy, will be significantly and positively related to persistence plans after controlling for SES, gender, and mathematics achievement.

2) Each of the five measures of subjective task value - STEM utility value, mathematics and science intrinsic values, and mathematics and science attainment values- will be significantly and positively associated with persistence plans after controlling for SES, gender, and mathematics achievement.

3) A positive perception of the cost of taking mathematics and science courses will be significantly and positively associated with persistence plans after controlling for SES, gender, and mathematics achievement.

\section{Methodology}

\section{Sample}

The High School Longitudinal Study of 2009 (Ingels et al., 2011) is a secondary longitudinal study from the National Center for Education Statistics (NCES). These data came from the base year of HSLS: 2009. The sample was representative of ninth grade students in public and private schools in the U.S. in 2009. Within each of the 944 participating schools, a 
stratified random sample of students was selected based on race/ethnicity. An average of 27 students per school were selected and the total number of students who participated in the study was 21,444 . Data were collected during the fall of the ninth grade. For this study, the analytic sample was reduced to the group of Black, Hispanic, and White students who were identified as having high-ability in mathematics or science. The group consisted of 1,757 students $(13.8 \%$ Black, 26.7\% Hispanic, and 59.6\% White) of whom $48.5 \%$ were female and $59.6 \%$ were male. Each group was analyzed separately ${ }^{1}$.

\section{Missing Data}

A total of 23 variables from HSLS: 2009 were used. Missing data percentages on items ranged from $0 \%$ to $4.8 \%$, with a mean of $2.4 \%(\mathrm{SD}=1.2 \%)$. The mechanism for missing data was assumed to be missing at random (Enders, 2010). Missing values for the independent variables were replaced using the Expectation Maximization (EM) procedure in SPSS 20.

\section{Weights}

The analyses were based on weighted samples that were created to adjust for oversampling bias and nonresponse (NCES, 2011). The first-year student weight (W1student) was used. To compensate for the way that SPSS calculates standard errors for weighted data based on population size rather than sample size, the weight was normalized and divided by the design effect (NCES, 2011).

\section{Variables}

Grouping variables. The analytic sample was selected using the variables of race and high-ability status. Race was provided by NCES and high-ability status was operationalized as

\footnotetext{
${ }^{1}$ An analysis of the entire group that included interactions of each variable with race revealed no significant interactions due to a lack of sufficient sample size to support a logistic regression analysis with a large number of predictor variables. Race has three levels; therefore adding the interactions of 11 variables with race created 22 additional independent variables.
} 
students who scored in the top $10 \%$ of their race group on the mathematics achievement test. This threshold was selected based the recent definition of giftedness as performance in the top $10 \%$ of the peer group (NAGC, 2011). Group-specific norms are recommended for the identification of ability in underrepresented groups (eg. Lohman, 2005). Students who met the mathematics achievement test criterion were identified as high ability (Table 1). The analytic sample was reduced to the 1,757 students who met the high-ability criteria.

Independent variables. Eleven independent variables were used to create a model for STEM persistence. Six of these variables were provided by NCES, and four others were created by the researchers. The development of each scale is described in this section.

Socioeconomic status. A standardized, continuous, composite variable was created by NCES based on parent/guardian education, occupation, and family income. Data for nonresponding parent/guardians were imputed by NCES.

NCES-Created Scales. Certain groups of items in the student survey were designed by NCES to be used as psychological scales (Ingels et al., 2011). The Eccles et al. (1983) expectancy-value framework was used in the design of HSLS: 2009. Therefore, these scales were used in the present study. These scales included: mathematics self-efficacy, science selfefficacy, mathematics identity, and science identity. All questionnaire items were reverse-coded such that larger scale values corresponded to positive attributes (Ingels et al., 2011). The reliability of each scale was assessed using Cronbach's Alpha; scales were required to meet a minimum threshold value of .65 . Scales were created and then standardized to a mean of zero and standard deviation of 1.0. These scales were created by NCES and used by the researchers for the present study. A summary of all scales and reliability coefficients is in Appendix B. 
Mathematics and science self-efficacy. Two scale scores represented math and science self-efficacy, respectively. The items used to construct this scale asked students about their beliefs in their abilities to be successful in the current math and science course. The math and science self-efficacy scales had Cronbach's Alphas of .90 and .88 respectively (Ingels et al., 2011).

Attainment value. Attainment value is based on the consistency of a mathematics or science identity with the student's identity, thus the mathematics and science identity scales that were created by NCES were used to represent mathematics and science attainment value, respectively. Students were asked how well they agreed with statements such as "You see yourself as a math (science) person" and "Others see you as a math (science) person." Math attainment value had a reliability of .84 and science attainment value had a reliability of .83 (Ingels et al., 2011).

\section{Researcher-Created Scales.}

Utility and intrinsic value. The researchers constructed scale scores for utility and intrinsic value. Student responses to a series of questions that probed the reasons why students planned to take more mathematics or science courses during high school were used to construct scales for the utility and intrinsic value of mathematics and science courses. Eight of these reasons were identified as representative of utility value or intrinsic value based on item content analysis (Table 2). Principal components analysis was used with the set of eight items for dimension reduction and three standardized factor scores were created that were labeled STEM utility value, mathematics intrinsic value, and science intrinsic value (Table 2).

STEM Utility value. Four of the eight questions asked students if they planned to take future math or science courses because they needed the courses to get into college or because the 
courses were useful for college. These four items loaded on one factor (Table 2). These factor loadings were used to create a standardized scale score for STEM Utility Value. The reliability for this scale was .87 .

Intrinsic value. Four of the eight questions asked students if they planned to take future math and science courses because they enjoyed or were good at math or science. The two science items loaded on factor two and the two math items loaded on factor three. The factor loadings were used to create a standardized scale score for Mathematics Intrinsic Value and the two science variables were used to create a scale score for Science Intrinsic Value (Table 2). The two scales had reliabilities of .68 and .73 respectively.

Cost. The researchers also constructed a scale for cost. Four questions concerned the impact of spending a lot of time and effort in math and science classes on the amount of time available to spend with friends, time to spend on other activities, popularity, and being made fun of. The four items were reverse coded such that higher values corresponded to more positive perceptions of cost and were used to create the cost scale. The Cronbach's Alpha for this scale was .75; the scale was normalized to a mean of zero and a standard deviation of 1.0.

Dependent variable. The dependent variable of this study was a dichotomous variable that indicated STEM pipeline status. Students who identified the occupation they expected to have at age 30 as: (1) computer and mathematical; (2) architecture and engineering; (3) life, physical, and social sciences; or (4) healthcare practitioners and technical occupations were identified as having planned to persist. An alternate criterion for selection was devised because a large number of students $(28.2 \%)$ responded with “don't know". If a student planned on taking four years of mathematics, four years of science, and at least one Advanced Placement or International Baccalaureate mathematics or science course during high school, the student was 
included. Students who met either of the two criteria - identification of a future STEM occupation or indication of intent to a plan to persist - were assigned the dependent variable value of "planned to persist".

\section{Logistic Regression Model}

The goal was to investigate the role that expectations for success and subjective task value had on student persistence plans within each group. A logistic regression examines the effects of the many independent variables on one dichotomous, dependent variable (Hosmer \& Lemshow, 2000). STEM persistence status was the dependent variable. Each regression was performed in steps with SES entered in the first step, gender in the second step, and mathematics achievement test score in the third step. The group of expectancy-value variables was entered in the fourth step. The variables were entered stepwise to retain only significant predictors in the model at each step. This allowed the examination of how the relationships between significant variables and the dependent variable evolved as additional factors were added.

The decision was made to separate the sample by race/ethnicity group and perform separate logistic regression analysis because the power of the analysis was limited. The number of independent variables in the model was so large that the introduction of interaction variable for each of the three levels of race/ethnicity with the 11 predictor variables created 22 potential interaction variables. The sample size, though considerable, was insufficient to support the simultaneous testing of all interaction variables. Therefore, separate analyses were conducted for each level of race/ethnicity to explore potential differences in the operation of the expectancy value model. Although this method fails to provide tests of statistical significance regarding differences in the regression coefficients or odds ratios between groups, it does provide a starting point for further investigations into between group differences. An implication of this 
methodological choice is that between group differences should be considered tentatively and further analyses are needed.

\section{Validity}

Threats to internal validity. This study had several threats to internal validity. First, although the researchers took care to select the survey items that best reflected the constructs within the expectancy value model, these items were all worded to describe student's expectancies and values about the mathematics and science courses that they were taking in 2009 and may not reflect their values about these subjects in other contexts, such as real-world applications. Second, a lack of a standardized measure of science achievement that led to the use of other variables as a proxy for science achievement. Third, the occupation classification method available in the HSLS: 2009 public use database limited the researchers' ability to precisely sort occupations into STEM and non-STEM categories. Fourth, manual adjustments were made to values calculated by SPSS 20 using the procedures recommended by NCES (Ingels et al., 2011) because the complex study design and weighting used in this dataset affected statistical significance measures. Next, the method used to handle missing values was limited by the capabilities of SPSS. Expectation Maximization was used instead of multiple imputation. Lastly, the model created in this analysis is only one possible model of STEM persistence plans, many other models are possible and another model may better explain the variations in persistence.

Threats to external validity. The operationalization of high-ability is a threat to external validity. The design of HSLS: 2009 determined what information was available to identify students in the sample as having high ability in mathematics and science. This operationalization may differ from other definitions; and thus impacts the results. 


\section{Results}

Students were identified as having high ability as described in the methods section. Using multiple criteria for identification acknowledged findings in the literature regarding the importance of domain-specific criteria and group-based norms for identification of high ability (eg. Lohman, 2005). The criterion for identification was different for each race group (Table 1).

The goal of this study was to identify the significant predictors of plans to persist for ninth grade, high-ability, students for each race/ethnicity group. Descriptive statistics for the predictor variables by persistence plan status and overall are displayed for each group (Tables 36). Examination of these data revealed differences between the three high-ability groups. In the Black group, persisters scored significantly higher than non-persisters in math achievement, science intrinsic value, and science attainment value. In the Hispanic group, persisters scored significantly higher than non-persisters in STEM utility value and science attainment value. In the White group, there were significant differences between persisters and non-persisters on science self-efficacy, science intrinsic value, math attainment value, and science attainment value. All differences favored the persister group.

In Table 6, the means for each race/ethnicity group are compared. Socioeconomic status and science attainment value evidence large differences between White students and Black or Hispanic students. The Black group and the Hispanic group had similar scores on some variables such as: math self-efficacy, math intrinsic value, cost, and math attainment value but these groups differed more on the science-related variables. The Hispanic group was more similar to the White group than the Black group in terms of science-related variables. Importantly, the selection of these high-ability students based on mathematics achievement test scores at the $90^{\text {th }}$ 
percentile or higher did not produce range restriction in the self-efficacy variables; the descriptive statistics do not indicate range restriction that would attenuate correlations.

Bivariate correlations were calculated for each pair of continuous predictor variables within each group (Tables 7-9). None of the sizes of the correlation coefficients raised concerns about collinearity (maximum correlation $=.60$ ). The math-related variables were moderately correlated and the science-related variables (self-efficacy, intrinsic value, and attainment value) were moderately correlated.

Hierarchical (stepwise) logistic regression analyses were used to examine demographic variables (SES, gender, and mathematics achievement) that previous research has identified as predictive of STEM persistence. In the third step, the expectancy-value factors were added (Tables 10-12 and Tables 13-15). The regressions were run stepwise backwards using the Wald criterion and the resulting models were verified using stepwise forward methods which confirmed the results.

\section{Overall Model}

SES, Gender, and Mathematics Achievement. The direct effect of socioeconomic status on ninth grade high-ability students' plans to persist in STEM was examined. Socioeconomic status did not significantly predict planned STEM persistence for any group of high-ability students; students from higher SES households were not significantly more likely to plan to persist. Therefore this variable was not retained in subsequent models. The effect of gender on persistence plans was not statistically significant for any group of high-ability students and it was not retained in subsequent models. Mathematics achievement did not significantly predict persistence for Hispanic or White students, but was a significant predictor for Black students. However, the selection of students using mathematics achievement as a criterion 
resulted in a restricted range for this variable; thus these effects were most likely attenuated for all groups.

Expectancy-Value Variables. The individual expectations of success variables, science and math self-efficacy, were not significant predictors of persistence plans for any high-ability group. Of the group of STV variables, science attainment value was significant for all three groups, while STEM utility value was identified as significant predictors of persistence only for Hispanic students. Students who held a higher attainment value for science were more likely to plan to persist. The degree to which students identified with science was predictive of plans to persist. No other variables were significant predictors of persistence.

The pseudo $\mathrm{R}^{2}$ for the final models were $.271, .195$, and .178 for the Black, Hispanic, and White groups respectively.

\section{Discussion}

The complex study design of HSLS: 2009 allows for inferences to be made to the larger population of US students who were in the ninth grade in Fall 2009. The 1,757 students represent 346, 096 high-ability, ninth-graders in 2009. This is the group to which inferences are made.

\section{Research Hypotheses}

The goal of this study was to examine the dynamic processes by which ninth-grade, highability, students made STEM persistence plans within each race/ethnicity group. It was hypothesized that expectations for success, STV, and cost would be significantly and positively related to persistence. The results of this analysis partially support the hypotheses. Hypothesis 1 was not supported in the final model. Neither of the self-efficacies predicted persistence plans. Hypothesis 2 was partially supported. The final model showed that three components of STV 
were positively and significantly related to persistence in the final models. One significant predictor was common to the three groups; science attainment value was a significant predictor of persistence plans for Black, Hispanic, and White students. STEM utility was a significant predictor for Hispanic students, but not for Black or White students. Science interest value and math attainment value were retained in the model for White students but had $p$-values of .097 and .088 , respectively. Hypothesis 3 was not supported. The cost variable was not a significant predictor of persistence for any group.

These findings suggest that ninth grade, high-ability students who have a higher attainment value for science are more likely to plan to persist in STEM (Odds Ratios (OR) of 2.479, 1.719, and 1.898 for Black, Hispanic, and White students respectively). For Hispanic students, a higher utility value was a predictor of persistence $(\mathrm{OR}=1.95)$, while for Black students, a higher Math Achievement was a predictor $(\mathrm{OR}=1.254)$. Mathematics and science self-efficacy did not play a significant role in persistence plans for these students. This finding contradicts other research that supported math self-efficacy as predictive of STEM persistence in mixed-ability groups of students (e.g. Mau, 2003; Simpkins, Davis-Kean, \& Eccles, 2006). However, no previous studies have examined such effects in groups of high-ability students.

\section{Effect of SES and Gender}

Socioeconomic status was not a significant predictor of persistence for high-ability students within each race/ethnicity group. This finding is encouraging because it implies that low SES students are not less likely to persist. However, the descriptive statistics for each group show a large disparity in SES between the groups. The mean SES for high-ability White students was .71, while the mean SES for high-ability Black or Hispanic students were .10 and -.08 respectively. Furthermore, the overall persistence rate of White (67\%) student was substantially 
larger than for Black (53\%) or Hispanic (53\%) students. Thus, an analysis of the overall group would show that SES is correlated to persistence because of the effect of the White group.

Another interesting finding of this study is that gender was not a significant predictor of persistence plans for any group. This suggests that among high-ability students there is no evidence of gender stereotyping with regard to STEM persistence plans. However, this result may be affected by the inclusion of the life sciences and health sciences in the STEM category because these domains tend to be pursued by larger numbers of females. The chi-square test of the effect of gender on persistence in the Black group showed that gender was significantly related to persistence $\left(\chi^{2}(1)=5.551, p=.019\right)$, but the effect was not significant in the logistic regression analysis, which may indicate a lack of power. In contrast to this finding for ninth grade students, the persistent underrepresentation of women in the STEM fields implies that females' expectancies and values for STEM may change after the ninth grade and negatively impact their persistence plans. This is supported by the findings of Archer and her colleagues who cite disparities between cultural expectations of femininity and stereotypical images of scientists as barriers to female participation in STEM (e.g. Archer et al., 2010; Archer et al., 2007). Archer found these effects earlier than the ninth grade, but she did not study high-ability students.

\section{Effect of Mathematics Achievement}

Students were selected as having high-ability if the mathematics achievement test score was at the $90^{\text {th }}$ percentile or above for their race/ethnicity group. The mathematics achievement score was included to control for differences in persistence due to math ability. The effect of mathematics achievement was only significant for high-ability, Black students. The odds ratio of 1.254 indicates that a one-point increase on the mathematics achievement test equated to a $25.4 \%$ 
greater chance of the student planning to persist. This test had a 70-point maximum and the mean score for high-ability, Black students was 54.15 points. This result may reflect the fact that the identification criteria for giftedness used by schools depends on global norms and not on groupbased norms. Thus, the Black students who were in the $90^{\text {th }}$ percentile or greater for their own group would not have been identified as having high-ability in their own schools because the $90^{\text {th }}$ percentile cutoff score for the White group was substantially larger. For example, in this study the mean score for the high-ability Black group (54.15) was below the $90^{\text {th }}$ percentile score for Whites (55.98). Thus, only the Black students who have the highest scores for their group will reach identification thresholds in a school with a large White majority. Such students would not be identified as having high ability and may not self-identify as high-ability students.

\section{Self-Efficacy and Persistence Plans}

One explanation as to why mathematics and science self-efficacy were not significant predictors of persistence plans in this sample may be because the self-efficacy measures were specific to students' perceptions of their ability to succeed in their ninth grade coursework. Selfefficacy regarding school science and mathematics may have a weak relationship with students' plans to pursue a STEM career. Expectations for success in a career may not be adequately represented by school subject self-efficacies. An alternative explanation is that students do not make connections between school science and mathematics and their future career plans. This explanation is supported by the findings of Archer et al. (2010) who found that school science was viewed by students as completely different than "real" science. Further evidence for this explanation is the relatively low STEM utility value scores for these high-ability students, which indicated that students did not find science very useful for college or career. However, this finding about the relationship between self-efficacy and persistence contradicts other research on 
STEM persistence, intentions, and goals that has found math self-efficacy to be predictive of persistence plans (Fouad \& Smith, 1996; Mau, 2003; Navarro et al., 2007). Notably, these studies did not include the subjective task value variables that were included in this study and were conducted with mixed-ability groups. Further research should examine the predictive value of self-efficacy on STEM persistence plans.

The present study included only high-ability students. Therefore it could be posited that this group of students has higher self-efficacy and that a restriction of range of this variable attenuated the relationship between self-efficacy and persistence. However, the data show that the correlations between achievement and mathematics or science self-efficacy are generally not significant (for Black or Hispanic students; Tables 7 and 8) or significant but small $(r=.18$ and $.22, p<.01$ for White students; Table 9). Furthermore, no restriction of range was observed in the self-efficacies of high-ability students (Table 6), thus the high-ability students in this sample do not appear to have much higher self-efficacies in mathematics and science than other students. Notably, these studies did not include the subjective task value variables that were included in this study and were conducted with mixed-ability groups. Further research should examine the predictive value of self-efficacy on STEM persistence plans.

\section{Subjective Task Value and Persistence Plans}

Subjective task value (STV) has four components: intrinsic value, utility value, attainment value, and cost. Students' development of each component of STV is affected by sociocultural factors and subsequent differences in STV may affect STEM persistence plans. In this section each of these components will be discussed.

Intrinsic Value. According to the Eccles et al. (1983) model, the development of students' intrinsic value of science depends on sociocultural factors. Historically, the traditional 
image of science is one of a quest for knowledge that is motivated by an intrinsic desire to know, even if the knowledge may not be relevant or useful and the pursuit of knowledge for its own sake may be viewed as a luxury of the privileged (Brickhouse, 1994). In this sample of students with high-ability in science and mathematics it was expected that science and mathematics intrinsic values would be significantly above average. However, this expectation was not supported by the descriptive statistics for each high-ability group. Significant differences were found in both science intrinsic value favoring White students (Table 6) over Black or Hispanic students and persisters over non-persisters in both groups (Tables 3-5). Furthermore, the mean science intrinsic scale z-score for the Black group was -.15, which is quite low for a high-ability sample. Thus, high-ability Black students had a much lower sense of science intrinsic value than high-ability Hispanic or White students, who had mean scores of .32 and .40 respectively. An explanation for lower science intrinsic interest may be that traditional science curricula are not personally relevant (Aikenhead, 1996; Barba, 1998; Bøe, Henriksen, Lyons, \& Schreiner (2011); Brickhouse, 1994). The idea that curricula should be relevant to all students is one of the key tenets of culturally responsive instruction (Barba, 1998; Ford, 2011). The intrinsic value scores showed large differences across groups; nonetheless, intrinsic value was not a significant predictor for any group at the $p=.05$ level. The lack of a connection between intrinsic interest in a subject and persistence is supported by Holmegaard, Madsen, and Ulriksen (2012) who found that many Danish high school students claimed that a STEM subject was their favorite subject, yet avoided STEM majors in college.

Utility value. Utility value measures how much students feel that science and mathematics courses are useful for future college or career plans. Such value is established when students are made aware of potential options for college or career and understand that 
mathematics and science coursework are important steps towards achieving such goals. The logistic regression models show that STEM utility value predicted the persistence plans of Hispanic students, but not for Black or White students. This difference indicates that for Hispanic students practical concerns of college and career take precedence over personal interest and enjoyment. Therefore, establishing the utility value of STEM is particularly important to motivating Hispanic students to take such courses. A lack of role models in the STEM fields is a barrier to the creation of utility value for STEM in Hispanic students (Hines, 2003). Interestingly, the values of STEM utility did not vary as much between race/ethnicity groups as some other variables did (Table 6), but STEM utility was predictive of persistence plans only for Hispanic students, and there was a large difference in mean STEM utility between Hispanic persisters and non-persisters (Table 4).

Attainment value. Higher science attainment values predicted the persistence plans of all students. This finding is supported by the previous studies of several researchers. In this study, science attainment value is based on how well the student's perception of the domain of science fits with the student's own identity. Aikenhead (1996) found that only 5 to $15 \%$ of students had a strong, positive sense of science attainment value and that this distinguished potential future scientists from other students. Oyserman and Destin (2010) explained differences in academic attainment as related to preferences for identity-congruent actions to identity-incongruent actions. Students who believe science and mathematics are identity-congruent will have a higher attainment value for these courses and be more likely to plan to persist. Aschbacher, Li, and Roth (2009) also documented strong relationships between aspirations, persistence, and identity in their longitudinal study of a diverse sample of high school students. Furthermore, Bøe et al. (2011) related the problem of declining rates of STEM career choice to an increased focus on the 
occupation as an expression of identity and the fulfillment of the self that exists in more developed countries. Thus, the findings of the present study and previous research support the conclusion that students may not be willing to consider careers for which the characteristic traits are dissonant with desired personality traits that are part of their identities.

Some students may be more willing to consider careers that do not align well with their preferred identities because of sociocultural differences. The degree of willingness to deny the desires of the individual in favor of the needs of the group has sociocultural origins. Ford (2012) described cultural differences between Blacks, Hispanics, and Whites that included variations in views of the importance of a unique personal identity or of the importance of service to the community. These cultural views create differences in how much students are willing to compromise their preferred identity to conform to the expectations of a STEM identity. For example, students from less developed countries may be more willing to adopt STEM identities and pursue such careers.

Science attainment value measures the degree to which the student identified himself or herself as a science person and is identified by others as science person. In this study, significant differences in science attainment value were found favoring White students over Black or Hispanic students and favoring persisters over non-persisters in all groups. Furthermore, the level of science identity was significantly related to persistence for all students. Therefore, methods to improve identity-congruence of STEM and desirable student identities should be of interest to educators. Such methods should address changing school STEM curricula to increase the emphasis on qualities that are valued by students because these qualities are congruent with students' identities. 
Cost. In this study, cost is the student's assessment of how much engagement in mathematics and science coursework will preclude other activities, require excessive effort, or affect relationships with peers. Cost was not found to be a significant predictor of persistence for any group. The White group had a slightly more positive sense of cost than the Black or Hispanic groups. However, this measure of cost references a more immediate cost - how time spent working on mathematics and sciences courses interferes with more desirable activities and may yield negative reactions from peers - compared to the more long-term social cost of adopting a stigmatized identity. Indeed, Holmegaard et al. (2012) found that students' avoided STEM identities that were in conflict with their ideal identities and this was a reason why these students who claimed STEM subjects as their favorite subjects did not pursue STEM degrees. In effect, this represents a different type of cost, and a concern for entering an occupation that may not lead to self-fulfillment compared to a concern for the reactions of others. The operationalization of cost in the present study is aligned with the Eccles et al. (1983) model; however, it may be that long-term social costs are more relevant to occupational choice decisions than the immediate cost measured in this study.

\section{Implications}

The subjective task value components of science attainment value, science intrinsic value, and STEM utility value are predictive of planned STEM persistence but these variables may operate differently in groups of Black, Hispanic, and White students. The separate models described in the present study are a first step in examining between group differences. Further analyses are needed to establish the statistical significance of between group differences. These models can provide guidance for the development of interventions that could increase the numbers of students who plan to persist in STEM. For all students, identity congruence is likely 
to be a consideration in STEM persistence plans. One implication of this finding is the need to find ways to increase the congruence between STEM identities and students' identities for all students. The second implication is that students need to be made more aware of the utility of science and mathematics courses in relation to their future goals for career and college. The third implication is that STEM teachers and curricula need to inspire interest in these subjects. In this section, recommendations are made for practice and future research.

Schools should encourage the development of science identity in high-ability students by incorporating culturally responsive teaching principles into science courses and gifted programs (Barba, 1998; Ford, 2011; Hines, 2003). Research has shown that minority students' interest in science was positively affected by the integration of culture into science (Hines, 2003). Barba (1998) explained that science teaching must be more harmonious with culturally syntonic variables. For example, science classes that emphasize individual competition and where grading is on a curve do not fit well with the learning styles of culturally different students who prefer to work more collaboratively and develop extended networks of support among their peers.

The manner in which courses are taught is important to the recruitment and retention of students in the STEM disciplines. Science courses need to shift from a traditional purpose of "weeding out" students who are believed to be not capable of science (Aikenhead, 1996) to a more progressive purpose of inspiring interest, scaffolding learning for all students, and scouting for talent. To serve this new purpose will require the use of research-based principles of teaching and learning with established effectiveness, that are also culturally responsive. Students must learn about the nature of science and how science knowledge is created so that they can realize that their own ideas are valuable. Teaching strategies that emphasize active learning and collaboration such as problem-based learning or inquiry are culturally responsive because 
students can investigate issues that are relevant to them and participate in building scientific knowledge. Introductory courses must be interesting and engaging to inspire students to continue studies in that discipline.

Minority students may consider science foreign because they do not learn about any scientists or inventors from backgrounds similar to their own or encounter scientists in their communities (Hines, 2003; Taningco, Mathew, \& Pachon, 2008). These students may internalize the idea that they cannot perform science or may feel that they must lose their racial identity to be assimilated into the culture of science. Culturally responsive teaching methods can increase student interest in science courses and facilitate students' crossings between their own culture and the culture of science. Science instructors should reduce language barriers to learning by connecting science language and students' native languages to develop students' skills in making "border crossings" between the different worlds they navigate in life (Aikenhead, 1996; Cooper, 2011). The adoption of culturally responsive teaching practices will facilitate increased identity congruence between student identities and a science identity and science attainment value will increase.

Science and mathematics teachers should strive to inspire interest in their subjects and to engage all students through culturally responsive teaching practices. Some school settings discourage interest and passion in gifted students (Fredricks, Alfeld, \& Eccles, 2009). Contexts that encourage interest and passion are characterized by: teachers who model enthusiasm, courses and assignments that present adequate challenge, and tasks that are meaningful, varied, and cognitively complex (Fredericks et al., 2009). These characteristics will encourage highability students to continue studies in that subject. To increase the utility value of mathematics and science, providing students with information and advice about career options and the 
corresponding educational requirements is critical. Students need accurate information about STEM careers and this information should be part of science curricula and high school career counseling. Schools can better support students through the provision of counselors and teachers who have similar backgrounds as their students. Furthermore, greater care must be taken to look for potential STEM talent in students and to encourage high-ability, students to persist in developing their talents in mathematics and science.

In this study, models for the persistence plans of three groups of ninth grade, high-ability, students were developed and compared. Differences in the predictive models between race groups revealed different relationships among the predictor variables. Understanding these differences between groups of students may help educators to become more culturally responsive. The finding that science attainment value is the strongest predictor of persistence plans for all groups is not surprising based on previous research. This study provides quantitative evidence based on the analysis of a large, nationally representative sample that complements the findings of previous, qualitative research on STEM persistence. The group of high-ability students is similar to Aikenhead's (1996) “potential scientists” (p. 15) and this analysis reveals that even many in this select group do not identify strongly with STEM and do not plan to persist. This problem is common to many highly developed and modernized countries (Bøe et al., 2011). Aikenhead (1996) posited that the subcultures of the life-worlds of students and the subculture of science must be understood so that teachers can facilitate the border crossings of students between these cultures. Almost twenty years later, the data from this study imply that the situation that Aikenhead (1996) described has not changed much and little progress has been made toward this end. The field of science education continues to struggle with reform efforts that appear to be in conflict with recent government mandates, driven by accountability for 
results without regard to the processes used to obtain those results (see Southerland, Smith, Sowell, \& Kittleson, 2007). Previous quantitative studies of STEM persistence have focused on the number and level of mathematics and science courses that students take in high school. The findings of this study, taken with previous work in this area, imply that merely pushing students to take rigorous courses will not increase STEM outcomes. As Holmegaard et al. (2012) found, students who like such courses may still not pursue STEM majors. What is needed is to increase the compatibility of the STEM identity and the identities of our students. 


\section{References}

Aikenhead, G. (1996). Science education: Border crossing into the subculture of science. Studies in Science Education, 27, 1-52.

Aschbacher, P. R., Li, E., \& Roth, E. J. (2009). Is science me? High school students' identities, participation and aspirations in science, engineering, and medicine. Journal of Research in Science Teaching, 47(5). doi:10.1002/tea.20353

Archer, L., Dewitt, J., Osborne, J., Dillon, J., Willis, B., \& Wong, B. (2010). "Doing" science versus "being" a scientist: Examining 10/11-year-old schoolchildren's constructions of science through the lens of identity. Science Education, 94(4), 617-639.

Archer, L., Hollingworth, S., \& Halsall, A. (2007). 'University is not for me - I'm a Nike person': Urban, working-class young people's negotiations of 'style', identity and educational en gagement. Sociology, 41(2), 219-237.

Atkinson, R. D., \& Mayo, M. (2011). Refueling the U.S. innovation economy: Fresh approaches to science, technology, engineering and mathematics (STEM) education. (pp. 1-178). Washington, DC: The Information Technology and Innovation Foundation.

Bandura, A., Barbaranelli, C., Caprara, G. V., \& Pastorelli, C. (2001). Self-efficacy beliefs as shapers of children's aspirations and career trajectories. Child Development, 72, 187-206. doi:10.1111/1467-8624.00273

Barba, R. H. (1998). Science in the multicultural classroom: A guide to teaching and learning ( $2^{\text {nd }}$ Ed.). Boston, MA: Allyn and Bacon.

Bøe, M. V., Henriksen, E. K., Lyons, T., \& Schreiner, C. (2011). Participation in science and technology: Young people's achievement-related choices in late-modern societies. Studies in Science Education, 47(1), 37-71. 
Bonous-Harnmarth, M. (2000). Pathways to success: Affirming opportunities for science, mathematics, and engineering majors. Journal of Negro Education, 69, 92-111.

Brickhouse, N. (1994). Bringing in the outsiders: Reshaping the sciences of the future. Journal of Curriculum Studies, 26(4), 401-416.

Cooper, C. R. (2011). Bridging multiple worlds: Cultures, identities, and pathways to college. New York, NY: Oxford University Press.

Cross, T. L., \& Coleman, L. J. (2005). School-based conception of giftedness. In R. J. Sternberg, \& J. E. Davidson, (Eds.), Conceptions of Giftedness ( $2^{\text {nd }}$ Ed.), Cambridge, UK: Cambridge University Press.

Eccles [Parsons], J. S., Adler, T. F., Futterman, R., Goff, S. B., Kaczala, C. M.,Meece, J. L., et al. (1983). Expectations, values and academic behaviors. In J.T. Spence (Ed.), Perspectives on achievement and achievement motivation (pp. 75-146). San Francisco: W. H. Freeman.

Eccles, J. S. (2005). Studying gender and ethnic differences in participation in math, physical science, and information technology. New Directions For Child And Adolescent Development, (110), 7-14. doi:10.1002/cd.146

Eccles, J. S. (2009). Who am I and what am I going to do with my life? Personal and collective identities as motivators of action. Educational Psychologist, 44, 78-89. doi:10.1080/00461520902832368

Enders, C. K. (2010). Applied missing data analysis. New York, NY: Guilford Press.

Erikson, E. H. (1968). Identity: Youth and crisis. New York, NY: Norton.

Ford, D. Y. (2011). Multicultural gifted education $\left(2^{\text {nd }}\right.$ Ed). Waco, TX: Prufrock Press. 
Fouad, N. A., \& Smith, P. L. (1996). A test of a social cognitive model for middle school students: Math and science. Journal of Counseling Psychology, 43, 338-346. doi: $10.1037 / 0022-0167.43 .3 .338$

Fredricks, J. A., Alfeld, C., \& Eccles, J. S. (2009). Developing and fostering passion in academic and nonacademic domains. Gifted Child Quarterly, 54(1), 18-30. doi:10.1177/0016986209352683

Heilbronner, N. N. (2011). Stepping onto the STEM pathway: Factors affecting talented students' declaration of STEM majors in college. Journal for the Education of the Gifted, 34, 876899. doi: 10.1177/0162353211425100

Hines, S. M. (2003). Multicultural science education: Theory, practice, and promise. New York, NY: Peter Lang Publishing.

Holmegaard, H., Madsen, L. M., \& Ulriksen, L. (2012). To choose or not to choose science: Constructions of desirable identities among young people considering a STEM higher education programme. International Journal of Science Education, doi:10.1080/09500693.2012.749362.

Hosmer, D. W., \& Lemeshow, S. (2000). Applied logistic regression (2 ${ }^{\text {nd }}$ Ed.). New York, NY: Wiley.

Ingels, S.J., Pratt, D.J., Herget, D.R., Burns, L.J., Dever, J.A., Ottem, R., Rogers, J.E., Jin, Y., \& Leinwand, S. (2011). High School Longitudinal Study of 2009 (HSLS:09). Base-Year Data File Documentation (NCES 2011-328). U.S. Department of Education. Washington, DC: National Center for Education Statistics. Retrieved from http://nces.ed.gov/surveys/hsls09/hsls09 data.asp 
Lee, O., \& Luykx, A. (2006). Science education and student diversity: Synthesis and research agenda. New York, NY: Cambridge University Press.

Lewis, B. F., \& Connell, S. (2005). African American students' career considerations and reasons for enrolling in advanced science courses. The Negro Educational Review, 56, 221-232.

Lohman, D. F. (2005). The role of nonverbal ability tests in identifying academically gifted students: An aptitude perspective. Gifted Child Quarterly, 49(2), 111-138. doi:10.1177/001698620504900203

Lynch, S. J. (2011). Equity and U.S. science education policy from the G.I. Bill to NCLB: From opportunity denied to mandated outcomes. In G. E. DeBoer (Ed.), The role of public policy in K-12 science education (pp. 305-354). Charlotte, NC: Information Age Publishing.

Maltese, A. V., \& Tai, R. H. (2011). Pipeline persistence: Examining the association of educational experiences with earned degrees in STEM among U.S. students. Science Education, 95, 877-907. doi:10.1002/sce.20441

Mau, W. C. (2003). Factors that influence persistence in science and engineering career aspirations. The Career Development Quarterly, 51, 234-243. doi:10.1002/j.21610045.2003.tb00604.x

National Academy of Sciences. (2007). Rising above the gathering storm: Energizing and employing America for a brighter economic future. Washington, DC: National Academy Press. Retrieved from http://www.nap.edu/catalog.php?record $\mathrm{id}=11463$ 
NAGC. (2011). Redefining giftedness for a new century: Shifting the paradigm. Retrieved on November 15, 2011 from http://www.nagc.org/index2.aspx?id=6404 Washington, DC: Author.

National Center for Education Statistics (NCES). (2011). High School Longitudinal Study: 2009 EDAT extract codebook. Washington, DC: Author. Retrieved from http://nces.ed.gov/surveys/hsls09/hsls09 data.asp

National Science Board. (2010). Preparing the next generation of STEM innovators: Identifying and developing our nation's human capital. Washington, D.C: National Science Foundation. Retrieved from http://www.nsf.gov/nsb/publications/2010/nsb1033.pdf

National Science Foundation. (2012, June). Women, minorities, and persons with disabilities in science and engineering [web page]. Retrieved from http://www.nsf.gov/statistics/wmpd/race.cfm

Navarro, R. L., Flores, L. Y., \& Worthington, R. L. (2007). Mexican American middle school students' goal intentions in mathematics and science: A test of social cognitive career theory. Journal of Counseling Psychology, 54, 320-335. doi: 10.1037/0022-016754.3 .320

Oyserman, D., \& Destin, M. (2010). Identity-based motivation: Implications for intervention. The Counseling Psychologist, 38, 1001-1043. doi: 10.1177/0011000010374775

Seymour, E., \& Hewitt, N. M. (1997). Talking about leaving: Why undergraduates leave the sciences. Boulder, CO: Westview Press.

Simpkins, S. D., \& Davis-Kean, P. E. (2005). The intersection between self-concepts and values: Links between beliefs and choices in high school. New Directions for Child and Adolescent Development, 110, 31-47. doi:10.1002/cd.148 
Simpkins, S. D., Davis-Kean, P. E., \& Eccles, J. S. (2006). Math and science motivation: A longitudinal examination of the links between choices and beliefs. Developmental Psychology, 42, 70-83. doi:10.1037/0012-1649.42.1.70

Southerland, S. A., Smith, L. K., Sowell, S. P., \& Kittleson, J. M. (2007). Chapter 2: Resisting unlearning: Understanding science education's response to the United States' national accountability movement. Review of Research in Education, 31(1), 45-77. doi:10.3102/0091732X06299015

Syed, M., Azmitia, M., \& Cooper, C. R. (2011). Identity and academic success among underrepresented ethnic minorities : An interdisciplinary review and integration. Journal of Social Issues, 67(3), 442-468.

Taconis, R., \& Kessels, U. (2009). How choosing science depends on students' individual fit to "science culture". International Journal of Science Education, 31(8), 1115-1132.

Tai, R. H., Liu, C. Q., Maltese, A. V., \& Fan, X. (2006). Planning early for careers in science. Science, 312, 1143-4. doi:10.1126/science.1128690

Taningco, M. T. V., Mathew, A. B., \& Pachon, H. P. (2008). STEM Professions: Opportunities and challenges for Latinos in science, technology, engineering, and mathematics. Los Angeles, CA: The Tomas Rivera Policy Institute. Retrieved from http://www.trpi.org/PDFs/STEM\%20Lit Final.pdf

Thompson, L. R., \& Lewis, B. F. (2005). Shooting for the stars: A case study of the mathematics achievement and career attainment of an African American male high school student. The High School Journal, 6-18.

Tyson, W., Lee, R., Borman, K. M., \& Hanson, M. A. (2007). Science, technology, engineering, and mathematics (STEM) pathways: High school science and math coursework and 
postsecondary degree attainment. Journal of Education for Students Placed at Risk, 12, 243-270. doi:10.1080/10824660701601266

U. S. Department of Education. (2008). 2007 elementary and secondary school survey. Washington, DC: Office for Civil Rights.

U. S. Department of Education, National Center for Education Statistics. (2011). The condition of education 2011, NCES 2011-033. Washington, DC: U.S. Government Printing Office.

Wigfield, A., \& Wagner, A. L. (2005). Competence, motivation, and identity development during adolescence (pp. 222-239) in A. J. Elliot \& C. S. Dweck (Eds.) Handbook of competence and motivation. New York, NY: The Guilford Press.

Zarrett, N. R., \& Malanchuk, O. (2005). Who's computing? Gender and race differences in young adults' decisions to pursue an information technology career. New Directions for Child and Adolescent Development, 2005 (110), 65-84. doi: 10.1002/cd.150 
Table 1

High Ability Criteria by Race

\begin{tabular}{lccc}
\hline & White & Black & Hispanic \\
\hline $\begin{array}{l}\text { Mathematics } \\
\text { Achievement Score }\end{array}$ & 55.98 & 49.59 & 51.56 \\
\hline
\end{tabular}

Source: High School Longitudinal Study of 2009. Tabulations by Author. Values not weighted. 
Table 2

Summary of Items and Factor Loadings for Varimax Orthogonal Three-Factor Solution for Utility and Intrinsic Value Items $(N=19,259)$

\begin{tabular}{|c|c|c|c|c|}
\hline \multirow[b]{2}{*}{ Item } & \multicolumn{3}{|c|}{ Factor Loadings } & \multirow[b]{2}{*}{ Communality } \\
\hline & 1 & 2 & 3 & \\
\hline $\begin{array}{l}\text { F02I Plans to take more math courses because it will } \\
\text { help to get into college. }\end{array}$ & .83 & .06 & .18 & .72 \\
\hline $\begin{array}{l}\text { F02J Plans to take more math courses because it will } \\
\text { be useful in college. }\end{array}$ & .81 & .09 & .23 & .72 \\
\hline $\begin{array}{l}\text { F05I Plans to take more science courses because it will } \\
\text { help to get into college. }\end{array}$ & .84 & .21 & .03 & .74 \\
\hline $\begin{array}{l}\text { F05J Plans to take more science courses because it } \\
\text { will be useful in college. }\end{array}$ & .83 & .25 & .05 & .76 \\
\hline $\begin{array}{l}\text { F05H Plans to take more science courses because } \\
\text { he/she enjoys studying science. }\end{array}$ & .15 & .87 & .12 & .80 \\
\hline $\begin{array}{l}\text { F05E Plans to take more science courses because } \\
\text { he/she is good at science }\end{array}$ & .21 & .84 & .16 & .77 \\
\hline $\begin{array}{l}\text { F02H Plans to take more math courses because he/she } \\
\text { enjoys studying math. }\end{array}$ & .08 & .15 & .86 & .76 \\
\hline $\begin{array}{l}\text { F02E Plans to take more math courses because he/she } \\
\text { is good at math. }\end{array}$ & .20 & .11 & .84 & .76 \\
\hline Eigenvalue & 3.63 & 1.33 & 1.06 & \\
\hline$\%$ of Variance & 45.40 & 16.66 & 13.30 & \\
\hline
\end{tabular}

Note: Boldface indicates highest factor loading 
Table 3

Descriptive Statistics for Predictor Variables as a Function of STEM Pipeline Status for HighAbility Black Students $(n=221)$

\begin{tabular}{|c|c|c|c|c|c|}
\hline & $\begin{array}{l}\text { Persisters } \\
(\mathrm{n}=119)\end{array}$ & $\begin{array}{c}\text { Non- } \\
\text { persisters } \\
(\mathrm{n}=102) \\
\end{array}$ & \multirow[t]{2}{*}{$\begin{array}{l}\text { Overall } \\
(\mathrm{n}=221)\end{array}$} & \multirow[t]{2}{*}{$\begin{array}{c}\chi^{2}(1) \\
\text { or } t(349)\end{array}$} & \multirow[t]{2}{*}{$\mathrm{p}$} \\
\hline & $\mathrm{M}(\mathrm{SE})$ & $\mathrm{M}(\mathrm{SE})$ & & & \\
\hline Female $^{\mathrm{a}}$ & 82 & 41 & 123 & \multirow{2}{*}{5.551} & \multirow{2}{*}{.019} \\
\hline Male $^{\mathrm{a}}$ & 50 & 48 & 98 & & \\
\hline $\mathrm{SES}^{\mathrm{b}}$ & $.22(.10)$ & $-.04(.06)$ & $.10(.06)$ & 1.346 & .184 \\
\hline $\begin{array}{l}\text { Math Achievement } \\
\text { Math Self- }\end{array}$ & $55.04(.31)$ & $53.12(.27)$ & $54.15(.26)$ & 2.088 & .042 \\
\hline Efficacy & $.58(.10)$ & $.32(.07)$ & $.46(.07)$ & 1.131 & .263 \\
\hline $\begin{array}{l}\text { Science Self- } \\
\text { Efficacy }^{\mathrm{b}}\end{array}$ & $.38(.18)$ & $.02(.06)$ & $.21(.10)$ & 1.223 & .227 \\
\hline $\begin{array}{l}\text { STEM Utility } \\
\text { Value }^{\mathrm{b}}\end{array}$ & $.53(.10)$ & $.35(.07)$ & $.44(.06)$ & .712 & .480 \\
\hline $\begin{array}{l}\text { Science Intrinsic } \\
\text { Value }^{\mathrm{b}}\end{array}$ & $.10(.16)$ & $-.44(.14)$ & $-.15(.10)$ & 2.019 & .049 \\
\hline $\begin{array}{l}\text { Math Intrinsic } \\
\text { Value }^{\mathrm{b}}\end{array}$ & $.33(.13)$ & $.23(.08)$ & $.28(.08)$ & .280 & .781 \\
\hline $\operatorname{Cost}^{\mathrm{b}}$ & $.00(.21)$ & $.30(.06)$ & $.14(.12)$ & 1.040 & .303 \\
\hline $\begin{array}{c}\text { Math Attainment } \\
\text { Value }^{\mathrm{b}}\end{array}$ & $.59(.09)$ & $.47(.06)$ & $.53(.06)$ & .522 & .604 \\
\hline $\begin{array}{c}\text { Science Attainment } \\
\text { Value }^{\mathrm{b}} \\
\end{array}$ & $.46(.11)$ & $-.20(.09)$ & $.15(.07)$ & 2.625 & .011 \\
\hline
\end{tabular}

Source: High School Longitudinal Study of 2009. Tabulations by Author. Data are weighted by W1Student.

${ }^{\mathrm{a}}$ Frequency.

${ }^{\mathrm{b}}$ Standardized score with an approximate mean of zero and approximate standard deviation of one. 
Table 4

Descriptive Statistics for Predictor Variables as a Function of STEM Pipeline Status for HighAbility Hispanic Students $(n=351)$

\begin{tabular}{|c|c|c|c|c|c|}
\hline & $\begin{array}{l}\text { Persisters } \\
(\mathrm{N}=217) \\
\end{array}$ & $\begin{array}{c}\text { Non- } \\
\text { persisters } \\
(\mathrm{N}=134) \\
\end{array}$ & \multirow[t]{2}{*}{$(\mathrm{n}=351)$} & \multirow[t]{2}{*}{$\begin{array}{c}\chi^{2}(1) \\
\text { or } t(219)\end{array}$} & \multirow[t]{2}{*}{$\mathrm{p}$} \\
\hline & $\mathrm{M}(\mathrm{SE})$ & $\mathrm{M}(\mathrm{SE})$ & & & \\
\hline Female $^{\mathrm{a}}$ & 103 & 77 & 180 & \multirow{2}{*}{3.022} & \multirow{2}{*}{.082} \\
\hline Male $^{\mathrm{a}}$ & 82 & 89 & 171 & & \\
\hline $\mathrm{SES}^{\mathrm{b}}$ & $.01(.06)$ & $-.19(.06)$ & $-.08(.05)$ & 1.393 & .167 \\
\hline $\begin{array}{l}\text { Math Achievement } \\
\text { Math Self- }\end{array}$ & $56.15(.25)$ & $55.02(.31)$ & $55.62(.19)$ & 1.611 & .110 \\
\hline Efficacy & $.48(.05)$ & $.54(.16)$ & $.51(.08)$ & .333 & .740 \\
\hline $\begin{array}{l}\text { Science Self- } \\
\text { Efficacy }^{b}\end{array}$ & $.50(.09)$ & $.24(.10)$ & $.37(.07)$ & 1.500 & .137 \\
\hline $\begin{array}{l}\text { STEM Utility } \\
\text { Value }^{\mathrm{b}}\end{array}$ & $.59(.07)$ & $.02(.10)$ & $.32(.06)$ & 3.327 & .001 \\
\hline $\begin{array}{l}\text { Science Intrinsic } \\
\text { Value }^{\mathrm{b}}\end{array}$ & $.50(.14)$ & $.13(.13)$ & $.32(.09)$ & 1.603 & .112 \\
\hline $\begin{array}{c}\text { Math Intrinsic } \\
\text { Value }^{\mathrm{b}}\end{array}$ & $.32(.12)$ & $.23(.16)$ & $.28(.10)$ & .396 & .693 \\
\hline $\operatorname{Cost}^{\mathrm{b}}$ & $.14(.09)$ & $.10(.05)$ & $.12(.05)$ & .229 & .819 \\
\hline $\begin{array}{c}\text { Math Attainment } \\
\text { Value } \\
\text { Science Attainment }\end{array}$ & $.68(.06)$ & $.54(.07)$ & $.61(.05)$ & .856 & .394 \\
\hline Value $^{\mathrm{b}}$ & $.64(.11)$ & $.12(.16)$ & $.39(.09)$ & 2.879 & .005 \\
\hline
\end{tabular}

Source: High School Longitudinal Study of 2009. Tabulations by Author. Data are weighted by W1Student.

${ }^{\mathrm{a}}$ Frequency.

${ }^{\mathrm{b}}$ Standardized score with an approximate mean of zero and approximate standard deviation of one. 
Table 5

Descriptive Statistics for Predictor Variables as a Function of STEM Pipeline Status for HighAbility White Students $(n=1,185)$

\begin{tabular}{|c|c|c|c|c|c|}
\hline & $\begin{array}{l}\text { Persisters } \\
(\mathrm{n}=804)\end{array}$ & $\begin{array}{c}\text { Non- } \\
\text { persisters } \\
(\mathrm{n}=381)\end{array}$ & $(\mathrm{n}=1,185)$ & $\begin{array}{c}\chi^{2}(1) \\
\text { or } t(1183)\end{array}$ & $\mathrm{p}$ \\
\hline & $\mathrm{M}(\mathrm{SE})$ & $\mathrm{M}(\mathrm{SE})$ & & & \\
\hline Female $^{\mathrm{a}}$ & 366 & 180 & 546 & \multirow{2}{*}{.061} & \multirow{2}{*}{.805} \\
\hline Male $^{\mathrm{a}}$ & 424 & 215 & 639 & & \\
\hline $\mathrm{SES}^{\mathrm{b}}$ & $.73(.03)$ & $.66(04)$ & $.71(.02)$ & .680 & .497 \\
\hline $\begin{array}{c}\text { Math Achievement } \\
\text { Math }\end{array}$ & $60.50(.13)$ & $59.91(.19)$ & $60.30(.12)$ & 1.235 & .218 \\
\hline $\begin{array}{l}\text { Self-Efficacy }^{b} \\
\text { Science Self- }\end{array}$ & $.68(.03)$ & $.47(.05)$ & $.61(.03)$ & 1.701 & .090 \\
\hline $\begin{array}{c}\text { Efficacy }^{\mathrm{b}} \\
\text { STEM Utility }\end{array}$ & $.68(.03)$ & $.21(.06)$ & $.52(.03)$ & 3.716 & .000 \\
\hline $\begin{array}{c}\text { Value }^{\mathrm{b}} \\
\text { Science Intrinsic }\end{array}$ & $.57(.03)$ & $.38(04)$ & $.51(.02)$ & 1.692 & .092 \\
\hline $\begin{array}{c}\text { Value }^{\mathrm{b}} \\
\text { Math Intrinsic }\end{array}$ & $.64(.04)$ & $-.07(.05)$ & $.40(.03)$ & 4.590 & .000 \\
\hline Value $^{\mathrm{b}}$ & $.76(.04)$ & $.56(.05)$ & $.69(.03)$ & 1.242 & .216 \\
\hline $\operatorname{Cost}^{b}$ & $.35(.04)$ & $.12(.05)$ & $.27(.02)$ & 1.783 & .076 \\
\hline $\begin{array}{c}\text { Math Attainment } \\
\text { Value }^{\mathrm{b}}\end{array}$ & $.95(.03)$ & $.60(.04)$ & $.83(.02)$ & 3.043 & .003 \\
\hline $\begin{array}{c}\text { Science Attainment } \\
\text { Value }^{\mathrm{b}}\end{array}$ & $.82(.03)$ & $.08(.06)$ & $.57(.03)$ & 5.819 & .000 \\
\hline
\end{tabular}

Source: High School Longitudinal Study of 2009. Tabulations by Author. Data are weighted by W1Student.

${ }^{a}$ Frequency.

${ }^{b}$ Standardized score with an approximate mean of zero and approximate standard deviation of one. 
Table 6

Comparison of Ninth Grade, High-Ability Students Across Race/Ethnicity Groups

\begin{tabular}{|c|c|c|c|}
\hline & $\begin{array}{c}\text { White } \\
(\mathrm{n}=1,185)\end{array}$ & $\begin{array}{c}\text { Black } \\
(\mathrm{n}=221)\end{array}$ & $\begin{array}{l}\text { Hispanic } \\
(\mathrm{n}=351)\end{array}$ \\
\hline & $\mathrm{M}(\mathrm{SD})$ & $\mathrm{M}(\mathrm{SD})$ & $\mathrm{M}(\mathrm{SD})$ \\
\hline Female $^{\mathrm{a}}$ & 546 & 123 & 180 \\
\hline Male $^{\mathrm{a}}$ & 639 & 98 & 171 \\
\hline $\mathrm{SES}^{\mathrm{b}}$ & $.71(.71)$ & $.10(.72)$ & $-.08(.74)$ \\
\hline Math Achievement & $60.30(3.41)$ & $54.15(3.43)$ & $55.62(3.54)$ \\
\hline Math Self-Efficacy ${ }^{\mathrm{b}}$ & $.61(.88)$ & $.46(.84)$ & $.51(.97)$ \\
\hline Science Self-Efficacy ${ }^{b}$ & $.52(.93)$ & $.21(1.06)$ & $.37(.88)$ \\
\hline STEM Utility Value $^{\mathrm{b}}$ & $.51(.82)$ & $.44(.93)$ & $.32(.91)$ \\
\hline Science Intrinsic Value ${ }^{b}$ & $.40(1.19)$ & $-.15(1.03)$ & $.32(1.19)$ \\
\hline Math Intrinsic Value ${ }^{b}$ & $.69(1.11)$ & $.28(1.19)$ & $.28(1.18)$ \\
\hline $\operatorname{Cost}^{b}$ & $.27(.91)$ & $.14(1.04)$ & $.12(.86)$ \\
\hline Math Attainment Value ${ }^{b}$ & $.83(.82)$ & $.53(.84)$ & $.61(.85)$ \\
\hline Science Attainment Value ${ }^{\mathrm{b}}$ & $.57(.96)$ & $.15(.96)$ & $.39(.95)$ \\
\hline
\end{tabular}

Source: High School Longitudinal Study of 2009. Tabulations by Author. Data are weighted by W1Student.

${ }^{\mathrm{a}}$ Frequency.

${ }^{\mathrm{b}}$ Standardized score with an approximate mean of zero and approximate standard deviation of one. 
Table 7

Intercorrelations for Predictor Variables of Planned STEM Persistence (High-Ability, Black Students)

\begin{tabular}{|c|c|c|c|c|c|c|c|c|c|c|}
\hline Measure & 1 & 2 & 3 & 4 & 5 & 6 & 7 & 8 & 9 & 10 \\
\hline 1. SES & 1 & & & & & & & & & \\
\hline 2. Math Self-efficacy & -.04 & 1 & & & & & & & & \\
\hline 3. Science Self-efficacy & .17 & .17 & 1 & & & & & & & \\
\hline 4. STEM Utility Value & .09 & -.08 & .15 & 1 & & & & & & \\
\hline 5. Science Intrinsic Value & -.07 & -.06 & $.29 *$ & -.02 & 1 & & & & & \\
\hline 6. Math Intrinsic Value & .03 & $.41 * *$ & -.23 & $-.32 *$ & .00 & 1 & & & & \\
\hline 7. Cost & -.09 & -.03 & .21 & .08 & .10 & -.15 & 1 & & & \\
\hline 8. Math Attainment Value & -.10 & $.60 * *$ & .10 & -.15 & .00 & $.51 * *$ & .09 & 1 & & \\
\hline 9. Science Attainment Value & .13 & .15 & $.53 * *$ & .19 & $.42 * *$ & -.04 & .08 & .27 & 1 & \\
\hline 10. Math Achievement Score & .11 & .05 & .01 & .11 & -.08 & -.13 & -.14 & -.01 & -.01 & 1 \\
\hline
\end{tabular}

Source: High School Longitudinal Study of 2009. Tabulations by Author. Data are weighted by W1Student. $* \mathrm{p}<.05 * * \mathrm{p}<.01 * * * \mathrm{p}<.001$ 
Table 8

Intercorrelations for Predictor Variables of Planned STEM Persistence (High-Ability, Hispanic Students)

\begin{tabular}{|c|c|c|c|c|c|c|c|c|c|c|}
\hline Measure & 1 & 2 & 3 & 4 & 5 & 6 & 7 & 8 & 9 & 10 \\
\hline 1. SES & 1 & & & & & & & & & \\
\hline 2. Math Self-efficacy & -.18 & 1 & & & & & & & & \\
\hline 3. Science Self-efficacy & .08 & $.31 * *$ & 1 & & & & & & & \\
\hline 4. STEM Utility Value & $.24 *$ & $-.23 *$ & .04 & 1 & & & & & & \\
\hline 5. Science Intrinsic Value & -.02 & .02 & $.42 * *$ & .00 & 1 & & & & & \\
\hline 6. Math Intrinsic Value & .11 & $.28 * *$ & .05 & -.07 & -.02 & 1 & & & & \\
\hline 7. Cost & $.21 *$ & $.18^{*}$ & $.24 *$ & .09 & .07 & .15 & 1 & & & \\
\hline 8. Math Attainment Value & .00 & $.39 * *$ & .18 & -.16 & .11 & $.53 * *$ & .06 & 1 & & \\
\hline 9. Science Attainment Value & .19 & -.04 & $.39 * *$ & .18 & $.45 * *$ & -.04 & .12 & .16 & 1 & \\
\hline 10. Math achievement & $.24 *$ & .18 & .15 & .04 & .16 & $.32 * *$ & .12 & $.35 * *$ & .12 & 1 \\
\hline
\end{tabular}

Source: High School Longitudinal Study of 2009. Tabulations by Author. Data are weighted by W1Student. $* \mathrm{p}<.05 * * \mathrm{p}<.01 * * * \mathrm{p}<.001$ 
Table 9

Intercorrelations for Predictor Variables of Planned STEM Persistence (High-Ability, White students)

\begin{tabular}{|c|c|c|c|c|c|c|c|c|c|c|}
\hline Measure & 1 & 2 & 3 & 4 & 5 & 6 & 7 & 8 & 9 & 10 \\
\hline 1. SES & 1 & & & & & & & & & \\
\hline 2. Math Self-efficacy & .01 & 1 & & & & & & & & \\
\hline 3. Science Self-efficacy & .02 & $.38 * *$ & 1 & & & & & & & \\
\hline 4. STEM Utility Value & -.01 & -.01 & .08 & 1 & & & & & & \\
\hline 5. Science Intrinsic Value & .11 & $.17 *$ & $.43 * *$ & -.01 & 1 & & & & & \\
\hline 6. Math Intrinsic Value & .06 & $.40 * *$ & .07 & -.08 & .09 & 1 & & & & \\
\hline 7. Cost & .01 & $.22 * *$ & $.29 * *$ & .03 & $.16^{*}$ & $.14^{*}$ & 1 & & & \\
\hline 8. Math Attainment Value & -.04 & $.50 * *$ & $.25 * *$ & .01 & .10 & $.50 * *$ & $.14^{*}$ & 1 & & \\
\hline 9. Science Attainment Value & .07 & $.17 * *$ & $.45 * *$ & .10 & $.56 * *$ & .04 & $.19 * *$ & $.29 * *$ & 1 & \\
\hline 10. Math Achievement Score & .12 & $.22 * *$ & $.18 * *$ & -.07 & .06 & $.20 * *$ & .07 & $.27 * *$ & .08 & 1 \\
\hline
\end{tabular}

Source: High School Longitudinal Study of 2009. Tabulations by Author. Data are weighted by W1Student. $* \mathrm{p}<.05 * * \mathrm{p}<.01 * * * \mathrm{p}<.001$ 
Table 10

Nested Models for the planned STEM persistence of high-ability, Black ninth grade students ( $N$ $=221$ )

\begin{tabular}{lllll}
\hline & 1 & 2 & 3 & 4 \\
Variables & & & & \\
\hline SES & ns & -- & -- & -- \\
Gender & & ns & -- & -- \\
Math achievement & & & 1.220 & $1.254^{*}$ \\
Science attainment & & & & $2.479^{*}$ \\
$\chi^{2}$ & & & 4.592 & 11.869 \\
$\Delta \chi^{2}$ & & & $4.592 *$ & $7.277^{*}$ \\
df & & & 1 & 2 \\
$\Delta$ df & & & 1 & 1 \\
Pseudo R ${ }^{2}$ & & & .112 & .271 \\
$\Delta$ Pseudo R & & & $.112 *$ & $.159 * *$ \\
\hline Source: High & & & \\
\hline
\end{tabular}

Source: High School Longitudinal Study of 2009. Tabulations by Author. Data are weighted by W1Student.

$* * * \mathrm{p}<.001, * * \mathrm{p}<.01, * \mathrm{p}<.05$ 
Table 11

Nested Models for the planned STEM persistence of high-ability, Hispanic ninth grade students $(N=351)$

\begin{tabular}{lllll}
\hline & 1 & 2 & 3 & 4 \\
Variables & & & & \\
\hline SES & ns & -- & -- & -- \\
Gender & & ns & -- & -- \\
Math Achievement & & & ns & -- \\
STEM utility & & & & $1.950^{* *}$ \\
Science attainment & & & & $1.719^{*}$ \\
$\chi^{2}$ & -- & -- & -- & 16.046 \\
$\Delta \chi^{2}$ & & -- & -- & $16.046^{* * *}$ \\
df & -- & -- & -- & 2 \\
$\Delta$ df & & -- & -- & 2 \\
Pseudo $\mathrm{R}^{2}$ & -- & -- & -- & .195 \\
$\Delta$ Pseudo R & & -- & -- & $.195^{* * *}$ \\
\hline Source: High School Lon
\end{tabular}

Source: High School Longitudinal Study of 2009. Tabulations by Author. Data are weighted by W1Student.

$* * * \mathrm{p}<.001, * * \mathrm{p}<.01, * \mathrm{p}<.05$ 
Table 12

Nested Models for the planned STEM persistence of high-ability, White ninth grade students ( $N$ $=1,148)$

\begin{tabular}{lllll}
\hline & 1 & 2 & 3 & 4 \\
Variables & & & & \\
\hline SES & ns & -- & -- & -- \\
Gender & & ns & -- & -- \\
Math Achievement Score & & & ns & -- \\
Science attainment & & & & $1.898^{* *}$ \\
$\chi^{2}$ & -- & -- & & 31.105 \\
$\Delta \chi^{2}$ & & -- & & $31.105^{* * *}$ \\
df & -- & -- & & 1 \\
$\Delta$ df & & -- & & 1 \\
Pseudo $\mathrm{R}^{2}$ & -- & -- & & .178 \\
$\Delta$ Pseudo $\mathrm{R}^{2}$ & & -- & & $.178^{* * *}$ \\
\hline
\end{tabular}

Source: High School Longitudinal Study of 2009. Tabulations by Author. Data are weighted by W1Student.

$* * * \mathrm{p}<.001, * * \mathrm{p}<.01,{ }^{*} \mathrm{p}<.05$, 
Table 13

Logistic Regression Models for STEM Persistence of High-Ability Black Students

\begin{tabular}{llcccccc}
\hline Model & Variables & B & SE & Wald & $\begin{array}{l}\text { Odds } \\
\text { Ratio }\end{array}$ & CI & $p$ \\
\hline 1 & SES & .545 & .410 & 1.764 & 1.725 & $0.772,3.856$ & .184 \\
2 & Female & .135 & .567 & 0.056 & 1.144 & $0.376,3.478$ & .812 \\
& & & & & & & \\
3 & Math achievement & .199 & .102 & 3.822 & 1.220 & $0.999,1.489$ & .051 \\
& & & & & & & \\
4 & $\begin{array}{l}\text { Math achievement } \\
\text { Science Attainment Value }\end{array}$ & .908 & .370 & 4.193 & 2.479 & $1.201,5.120$ & .014
\end{tabular}

Source: High School Longitudinal Study of 2009. Tabulations by Author. Data are weighted by W1Student. 
Table 14

Logistic Regression Models for STEM Persistence of High-Ability Hispanic Students

\begin{tabular}{llcccccc}
\hline Model & Variables & B & SE & Wald & $\begin{array}{l}\text { Odds } \\
\text { Ratio }\end{array}$ & CI & p \\
\hline 1 & SES & .381 & .276 & 1.907 & 1.464 & $0.852,2.514$ & .167 \\
2 & Female & .375 & .399 & 0.885 & 1.456 & $0.666,3.182$ & .347 \\
3 & Math achievement & .095 & .060 & 2.496 & 1.099 & $0.978,1.236$ & .114 \\
& & & & & & & \\
4 & $\begin{array}{l}\text { STEM Utility } \\
\text { Science Attainment }\end{array}$ & .568 & .246 & 7.393 & 1.950 & $1.205,3.157$ & .007 \\
& & & .238 & 5.183 & 1.719 & $1.078,2.741$ & .023
\end{tabular}

Source: High School Longitudinal Study of 2009. Tabulations by Author. Data are weighted by W1Student. 
Table 15

Logistic Regression Models for STEM Persistence of High-Ability White Students

\begin{tabular}{llcccccc}
\hline Step & Variables & B & SE & Wald & $\begin{array}{c}\text { Odds } \\
\text { Ratio }\end{array}$ & CI & $\mathrm{p}$ \\
\hline 1 & SES & .137 & .200 & .465 & 1.146 & $0.774,1.697$ & .496 \\
2 & Female & .029 & .283 & .010 & 1.029 & $0.591,1.792$ & .919 \\
& & & & & & & \\
3 & Math achievement & .053 & .043 & 1.519 & 1.054 & $.969,1.146$ & .218 \\
& & & & & & & \\
4 & Science interest & .258 & .155 & 2.760 & 1.294 & $0.955,1.755$ & .097 \\
& $\begin{array}{l}\text { Math attainment } \\
\text { Science attainment }\end{array}$ & .326 & .191 & 2.903 & 1.385 & $0.952,2.015$ & .088 \\
& .641 & .206 & 9.707 & 1.898 & $1.268,2.841$ & .002
\end{tabular}

Source: High School Longitudinal Study of 2009. Tabulations by Author. Data are weighted by W1Student. 


\section{Appendix A}

List of Questions Used to Construct Expectancy Value Scales

\begin{tabular}{|c|c|c|}
\hline Scale & Question & Responses \\
\hline & $\begin{array}{l}\text { (questions asked separately for } \\
\text { math/science) }\end{array}$ & \\
\hline & $\begin{array}{l}\text { What are the reasons you plan to take more } \\
\text { math/science courses during high school? }\end{array}$ & \\
\hline STEM Utility & -Because will help get into college & Yes/no \\
\hline STEM Utility & -Because it will be useful in college & Yes/no \\
\hline $\begin{array}{l}\text { Math/science } \\
\text { intrinsic }\end{array}$ & $\begin{array}{l}\text {-Because he/she enjoys studying } \\
\text { math/science }\end{array}$ & Yes/no \\
\hline $\begin{array}{l}\text { Math/science } \\
\text { intrinsic }\end{array}$ & -Because he/she is good at math/science & Yes/no \\
\hline $\begin{array}{l}\text { Math/science } \\
\text { attainment }\end{array}$ & You see yourself as a math/science person & 4-pt Likert \\
\hline $\begin{array}{l}\text { Math/science } \\
\text { attainment }\end{array}$ & Others see you as a math/science person & 4-pt Likert \\
\hline $\begin{array}{l}\text { Math/Science } \\
\text { self-efficacy }\end{array}$ & $\begin{array}{l}\text { You are confident that you can do an } \\
\text { excellent job on tests in this course }\end{array}$ & 4-pt Likert \\
\hline $\begin{array}{l}\text { Math/Science } \\
\text { self-efficacy }\end{array}$ & $\begin{array}{l}\text { You are certain that you can understand the } \\
\text { most difficult material presented in the } \\
\text { textbook used in this course }\end{array}$ & 4-pt Likert \\
\hline $\begin{array}{l}\text { Math/Science } \\
\text { self-efficacy }\end{array}$ & $\begin{array}{l}\text { You are certain that you can master the } \\
\text { skills being taught in this course }\end{array}$ & 4-pt Likert \\
\hline \multirow[t]{3}{*}{$\begin{array}{l}\text { Math/Science } \\
\text { self-efficacy }\end{array}$} & $\begin{array}{l}\text { You are confident that you can do an } \\
\text { excellent job on assignments in this course }\end{array}$ & 4-pt Likert \\
\hline & $\begin{array}{l}\text { (questions not asked separately for math and } \\
\text { science) }\end{array}$ & \\
\hline & $\begin{array}{l}\text { If you spend a lot of time and effort in your } \\
\text { math and science classes... }\end{array}$ & \\
\hline Cost & $\begin{array}{l}\text { You won't have enough time for hanging } \\
\text { out with your friends }\end{array}$ & 4-pt Likert \\
\hline Cost & $\begin{array}{l}\text { You won't have enough time for } \\
\text { extracurricular activities }\end{array}$ & 4-pt Likert \\
\hline Cost & You won't be popular & 4-pt Likert \\
\hline Cost & People will make fun of you & 4-pt Likert \\
\hline
\end{tabular}


Appendix B

Scales and Reliabilities

\begin{tabular}{llll}
\hline Scale & Created by & Number of Items & Alpha \\
\hline Cost & Researcher & 4 & .75 \\
Math Attainment Value & NCES & 2 & .84 \\
Math Intrinsic Value & Researcher & 2 & .68 \\
Math Self-Efficacy & NCES & 4 & .90 \\
Science Attainment Value & NCES & 2 & .83 \\
Science Intrinsic Value & Researcher & 2 & .73 \\
Science Self-Efficacy & NCES & 4 & .88 \\
STEM Utility Value & Researcher & 4 & .87 \\
\hline
\end{tabular}

